\title{
Studies on Sensory Analysis of Goat Milk Whey based Herbal Beverage
}

\author{
Nimish Kumar Lall ${ }^{1}$, Sandeep G.M. Prasad ${ }^{2}$, Binod Kumar Bharti ${ }^{3}$, Manisha Prasad ${ }^{4}$, \\ Nikhil Sharma ${ }^{5}$ and Mohd Nayeem Ali ${ }^{*}$
}

${ }^{1}$ Dairy Technology, Warner College of Dairy Technology, SHUATS, Prayagraj (UP), India

${ }^{2}$ Warner College of Dairy Technology, SHUATS, Prayagraj (UP), India

${ }^{3}$ SGIDT (Bihar Animal Sciences University) Patna (Bihar), India

${ }^{4}$ Lucknow Christian College, Lucknow (UP), India

${ }^{5}$ Warner College of Dairy Technology, SHUATS, Prayagraj (UP), India

${ }^{6}$ Department of Agriculture, Mahaveer Institute of Technology, Meerut (UP), India

*Corresponding author

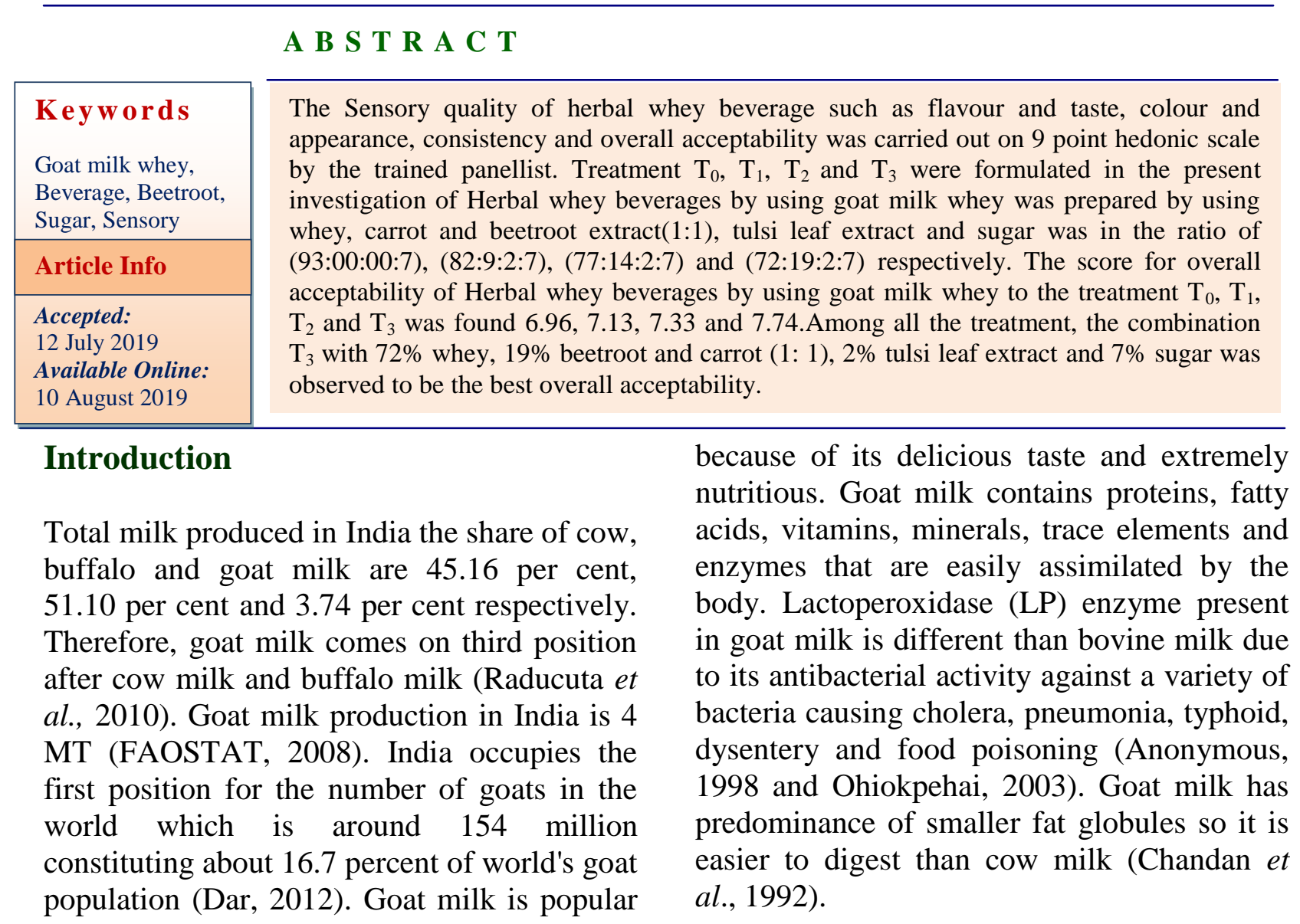


Whey is the largest by-product of the world dairy industry. It has greenish yellow colour in watery part of milk remaining after curd separation and that results from coagulation or fermentation carried out by acid, microbes or enzymes during manufacture of paneer, cheese, casein, chakka and chhana. The nutritive value of whey is higher due to presence of soluble nutrients in milk, particularly lactose, whey proteins, vitamins and minerals (Goyal and Gandhi, 2009). Whey obtained from goat milk has higher levels of alpha lactalbumin but is often discarded, or given to animals as nutritional supplement (Pandya and Ghodke, 2007). The conversion of whey into variety of beverages has an economic advantage, as the whole quantity is being used and there is no problem of left over residues. Whey also improves the economic viability of dairy plant (Shaikh et al., 2001).

Carrot is a cool season crop grown as an annual. It is an inexpensive and highly nutritious vegetable. Carrot contains appreciable amounts of vitamins $\mathrm{B}_{1}, \mathrm{~B}_{2}, \mathrm{~B}_{6}$ and carotenes. Dietary carotenes are associated with lower risk of many cancers. Vitamin A is an antioxidant and it plays a key role in growth and repair of tissues in addition to help the body to fight with infections. It keeps eyes healthy and nourish epithelial tissues in the lungs and skin (Singh et al., 2006). Carrot juice also helps to cleanse the liver and excrete fats and bile from body. It improves gastrointestinal health. Carrot juice is an effective food remedy in appendicitis, colitis, peptic ulcer, heart disease and bronchitis (Singh et al., 2006).

Beetroot (Beta vulgaris) is an herbaceous biennial from Chenopodiaceae family and has several varieties with bulb colours ranging from yellow to red. Deep red-coloured beetroots are the most popular for human consumption for both cooked and raw as salad or juice. Beetroot is use of natural food colours, because synthetic dyes are becoming more and more critically assessed by the consumer. In food processing, as compared with anthocyanin and carotenoids, betalains are less used. Beetroot powder or extracted pigments are used to improve the red colour of tomato pastes, sauces, soups, desserts, jams, jellies, sweets, ice creams and breakfast cereals. It also contributes to consumers health and wellbeing because it have antioxidants, because of the presence of nitrogen pigments called betalains, it is mainly comprise of red-violet-coloured betacyanins (betanin, isobetanin, probetanin and neobetanin) and yellow-orange-coloured betaxanthyns (Singh and Singh, 2014).

Tulsi is also known as 'Sacred Basil' or 'Holy Basil'. The botanical name of tulsi is Ocinum tenuiflorum or Ocinum santum. Ocinum tenuiflorum is a biannial (Kothari et al., 2004). It primarily occurs in green (Sri or Lakshmi tulsi) and purple (Krishna tulsi) morphotypes. In India tulsi are used for religious and medicinal purposes.The essential oil has either phenolic constituents such as eugenol, thymol alcohols as single major oil ingredients and terpene compounds as minor constituents (Kothari, 2004).

\section{Materials and Methods}

The experiment "Studies on sensory analysis of goat milk whey based herbal beverage" was carried out in research lab, Warner College of Dairy Technology, Sam Higginbottom University of Agriculture Technology and Sciences, Prayagraj-211007, U.P. (India).

\section{Procurement and collection of ingredients}

a) Milk: Milk was purchased from near village of Prayagraj.

b) Beetroot Carrot: Beetroot Carrot was 
purchased from local market of Prayagraj.

c) Tulsi: Tulsi was purchased from local market of Prayagraj.

d) Sugar: Sugar was purchased from local market of Prayagraj.

\section{Treatment combination}

$\mathrm{T}_{0}$-Control prepared from whey and sugar (93:7)

$\mathrm{T}_{1}$-Experimental sample prepared from whey, beetroot carrot, tulsi and Sugar (82:9:2:7)

$\mathrm{T}_{2}$-Experimental sample prepared from whey, beetroot carrot, tulsi and Sugar (77:14:2:7)

$\mathrm{T}_{3}$-Experimental sample prepared from whey, beetroot carrot, tulsi and Sugar (72:19:2:7)

\section{Preparation of paneer whey}

Goat milk heating at $85^{\circ}$ and cooling at $70^{\circ}$ and addition of $1 \%$ coagulant, continuously stirring and then coagulation at $70^{\circ} \mathrm{C}$ filtration it through Muslin cloth and obtained paneer whey.

\section{Preparation of herbal whey beverage}

Paneer whey heating at $45^{\circ}$ for $3 \mathrm{~min}$. and addition of sugar at $7 \%$ in each treatment then further add beetroot carrot extract with tulsi (2\% in each treatment) and mixing as per treatment combination of whey, beetroot carrot, tulsi and sugar and fill beverage in glass bottles, pasteurized at $63^{\circ}$ for $30 \mathrm{~min}$ then cool and storage at $5^{\circ}$.

\section{Organoleptic quality: (9 Point hedonic scale)}

Sensory evaluation of goat milk whey based herbal beverage

The sensory evaluation of goat milk whey based herbal beverage samples was done by a panel of judge using a 9 point hedonic scale.
The experienced Technical staff members of the Warner college of Dairy Technology, Sam Higginbottom University of Agriculture, Technology and Sciences, Prayagraj served as a judging team and evaluated the samples of different treatment of goat milk whey based herbal beverage. Numerical score were allocated for flavour and taste, colour and appearances, consistency and overall acceptability of herbal whey beverage.

\section{Statistical analysis}

The data will be analyzed statically by Analysis of variance (ANOVA) at 5\% level of significance and Critical Difference (C.D) in WASP software and excel software.

\section{Results and Discussion}

The results obtained from the analysis of goat milk whey based herbal beverage are presented on the sensory characteristics (9 point Hedonic scale) such as flavour and taste, colour and appearances, consistency and overall acceptability (Table 1-5).

\section{Flavour and taste of herbal whey beverage}

Flavour and taste score in control and experimental herbal whey beverage are presented in Table 2, The score for flavour and taste of herbal whey beverage sample of $\mathrm{T}_{0}, \mathrm{~T}_{1}, \mathrm{~T}_{2}$ and $\mathrm{T}_{3}$ was $7.12,7.30,7.52$ and 8.10 respectively. It was observed that highest mean of flavour and taste was recorded in the sample of $T_{3}(8.10)$ followed by $T_{2}(7.52)$, $\mathrm{T}_{1}(7.30)$ and $\mathrm{T}_{0}(7.12)$.

It was observed from the result of ANOVA, F (Cal) value (9.451) was greater than the table of $F$ tab (3.23) at 5\% level of significance. It indicates significant effect of treatment on flavour and taste. The significant difference was further analyzed statistically to find out the C.D. between and within the different 
treatment combinations. The difference between the mean values of $\mathrm{T}_{0}-\mathrm{T}_{1}(0.18), \mathrm{T}_{0^{-}}$ $\mathrm{T}_{2}(0.40)$ and $\mathrm{T}_{1}-\mathrm{T}_{2}(0.22)$ less than the C.D. value, 0.415 . Therefore, the difference was non significant and the difference between the mean values of $\mathrm{T}_{0}-\mathrm{T}_{3}(0.98), \mathrm{T}_{1}-\mathrm{T}_{3}(0.80)$ and $\mathrm{T}_{2}-\mathrm{T}_{3}$ (0.58) greater than the C.D. value, 0.415.Therefore, the difference was significant.

\section{Colour and appearance of herbal whey beverage}

Colour and appearance score in control and experimental herbal whey beverage reveals in Table 3, the mean score for colour and appearance of herbal whey beverage sample of $\mathrm{T}_{0}, \mathrm{~T}_{1}, \mathrm{~T}_{2}$ and $\mathrm{T}_{3}$ was to be $7.00,7.14,7.42$ and 7.66 respectively. It was observed that highest mean of colour and appearance was recorded in the sample of $\mathrm{T}_{3}(7.66)$ followed by $\mathrm{T}_{2}(7.42), \mathrm{T}_{1}(7.14)$ and $\mathrm{T}_{0}(7.00)$. This indicates that, increased in proportion of beetroot carrot in the blend increased the score for consistency of treatment of herbal whey beverage has significant effect $(p<0.05)$.

As evident from the result of ANOVA result indicates that the $\mathrm{F}(\mathrm{Cal})$ value (3.819) was greater than the table of $\mathrm{F}(3.23)$ at $5 \%$ level of significance.

The significant difference was further analyzed statistically to find out the C.D. between and within the different treatment combinations.

The difference between the mean values of $\mathrm{T}_{0}-\mathrm{T}_{1}(0.14), \mathrm{T}_{0}-\mathrm{T}_{2}(0.42)$ and $\mathrm{T}_{1}-\mathrm{T}_{2}(0.28)$ less than the C.D. value, 0.451 . Therefore, the difference was non significant and the difference between the mean values of $\mathrm{T}_{0}-\mathrm{T}_{3}$ (0.66), $\mathrm{T}_{1}-\mathrm{T}_{3}(0.52)$ and $\mathrm{T}_{2}-\mathrm{T}_{3}(0.24)$ greater than the C.D. value, 0.451. Therefore, the difference was significant.

\section{Consistency score of herbal whey beverage}

The data pertaining to consistency in control and experimental herbal whey beverage sample of different treatments are presented in Table 4. The mean value of treatment $\mathrm{T}_{0}$, $\mathrm{T}_{1}, \mathrm{~T}_{2}$ and $\mathrm{T}_{3}$ was found to be $6.78,6.96,7.08$ and 7.36 respectively. Highest mean score of consistency was recorded in the sample of $\mathrm{T}_{3}(7.36)$ followed by $\mathrm{T}_{2}(7.08), \mathrm{T}_{1}(6.96)$ and $\mathrm{T}_{0}(6.78)$.

The result of ANOVA indicates that the $F$ (Cal) value (5.391) was greater than the table of F (3.23) at 5\% level of significance. The significant difference was further analyzed statistically to find out the C.D. between and within the different treatment combinations. The difference between the mean values of $\mathrm{T}_{0}-\mathrm{T}_{1}(0.18), \mathrm{T}_{0}-\mathrm{T}_{2}(0.30), \mathrm{T}_{1}-\mathrm{T}_{2}(0.12)$ and $\mathrm{T}_{2}-\mathrm{T}_{3}$ (0.28)less than the C.D. value, 0.314 . Therefore, the difference was non significant and the difference between the mean values of $\mathrm{T}_{0}-\mathrm{T}_{3}(0.58), \mathrm{T}_{1}-\mathrm{T}_{3}(0.40)$ and $\mathrm{T}_{2}-\mathrm{T}_{3}(0.28)$ greater than the C.D. value, 0.314. Therefore, the difference was significant.

\section{Overall acceptability score of herbal whey beverage}

Overall acceptability score in control and experimental herbal whey beverage are shown in Table 5. The mean score for overall acceptability of herbal whey beverage sample of $\mathrm{T}_{0}, \mathrm{~T}_{1}, \mathrm{~T}_{2}$ and $\mathrm{T}_{3}$ was 6.96, 7.13, 7.33 and 7.74 respectively. It was observed that highest mean of overall acceptability score was recorded in the sample of $\mathrm{T}_{3}(7.74)$ followed by $\mathrm{T}_{2}(7.33), \mathrm{T}_{1}(7.13)$ and $\mathrm{T}_{0}(6.96)$. This indicates that, increased in proportion of beetroot carrot and tulsi in the blend, increased the score for overall acceptability of herbal whey beverage has significant effect $(p<0.05)$ between treatments (Fig. 1). 
Table.1 Sensory parameters of control and experimental goat milk whey based herbal beverage

\begin{tabular}{|l|c|c|c|c|}
\hline Particulars & $\mathbf{T}_{\mathbf{0}}$ & $\mathbf{T}_{\mathbf{1}}$ & $\mathbf{T}_{\mathbf{2}}$ & $\mathbf{T}_{\mathbf{3}}$ \\
\hline Flavour and taste & $7.12 \pm 0.29$ & $7.30 \pm 0.27$ & $7.52 \pm 0.28$ & $8.10 \pm 0.33$ \\
\hline Colour and appearance & $7.00 \pm 0.12$ & $7.14 \pm 0.21$ & $7.42 \pm 0.40$ & $7.66 \pm 0.47$ \\
\hline Consistency & $6.78 \pm 0.44$ & $6.96 \pm 0.23$ & $7.08 \pm 0.27$ & $7.36 \pm 0.23$ \\
\hline Overall acceptability & $6.96 \pm 0.13$ & $7.13 \pm 0.17$ & $7.33 \pm 0.30$ & $7.74 \pm 0.22$ \\
\hline
\end{tabular}

Table shown Mean \pm S.D.

Table.2 Flavour and taste score in control and experimental goat milk whey based herbal beverage

\begin{tabular}{|l|c|c|c|c|}
\hline \multirow{2}{*}{ Replication } & \multicolumn{3}{|c|}{ Treatment } \\
\cline { 2 - 5 } & $\mathrm{T}_{0}$ & $\mathrm{~T}_{1}$ & $\mathrm{~T}_{2}$ & $\mathrm{~T}_{3}$ \\
\hline R1 & 6.80 & 7.00 & 7.00 & 7.70 \\
\hline R2 & 7.60 & 7.00 & 7.50 & 8.50 \\
\hline R3 & 7.10 & 7.50 & 7.50 & 8.40 \\
\hline R5 & 7.00 & 7.50 & 7.80 & 8.00 \\
\hline Mean & 7.10 & 7.50 & 7.80 & 7.90 \\
\hline Max & 7.12 & 7.30 & 7.52 & 8.10 \\
\hline Min & 7.60 & 7.50 & 7.80 & 8.50 \\
\hline CD value (5\%) & 0.415 & 7.00 & 7.00 & 7.70 \\
\hline
\end{tabular}

Table.3 Colour and appearance score in control and experimental goat milk whey based herbal beverage

\begin{tabular}{|l|l|l|l|l|}
\hline \multirow{2}{*}{ Replication } & \multicolumn{3}{|c|}{ Treatment } \\
\cline { 2 - 5 } & $\mathrm{T}_{0}$ & $\mathrm{~T}_{1}$ & $\mathrm{~T}_{2}$ & $\mathrm{~T}_{3}$ \\
\hline R1 & 7.20 & 7.20 & 7.00 & 7.30 \\
\hline R2 & 7.00 & 7.00 & 7.00 & 7.50 \\
\hline R4 & 6.90 & 7.50 & 7.50 & 7.50 \\
\hline R5 & 7.00 & 7.00 & 7.80 & 8.50 \\
\hline Mean & 6.90 & 7.00 & 7.80 & 7.50 \\
\hline Max & 7.00 & 7.14 & 7.42 & 7.66 \\
\hline Min & 7.20 & 7.50 & 7.80 & 8.50 \\
\hline C.D. value (5\%) & 0.451 & & & 7.30 \\
\hline
\end{tabular}


Table.4 Consistency score in control and experimental goat milk whey based herbal beverage

\begin{tabular}{|l|c|c|c|c|}
\hline \multirow{2}{*}{ Replication } & \multicolumn{4}{|c|}{ Treatment } \\
\cline { 2 - 5 } & T0 & T1 & T2 & T3 \\
\hline R1 & 6.80 & 6.60 & 6.60 & 7.30 \\
\hline R3 & 6.90 & 7.10 & 7.20 & 7.00 \\
\hline R4 & 6.70 & 7.20 & 7.20 & 7.60 \\
\hline R5 & 7.00 & 7.00 & 7.10 & 7.50 \\
\hline Mean & 6.50 & 6.90 & 7.30 & 7.40 \\
\hline Max & 6.78 & 6.96 & 7.08 & 7.36 \\
\hline Min & 7.00 & 7.20 & 7.30 & 7.60 \\
\hline C.D. value (5\%) & 0.314 & 6.60 & 6.60 & 7.00 \\
\hline
\end{tabular}

Table.5 Overall acceptability score in control and experimental goat milk whey based herbal beverage

\begin{tabular}{|l|c|c|c|c|}
\hline \multirow{2}{*}{ Replication } & \multicolumn{4}{|c|}{ Treatment } \\
\cline { 2 - 5 } & T0 & T1 & T2 & T3 \\
\hline R1 & 6.93 & 6.93 & 6.86 & 7.43 \\
\hline R3 & 7.16 & 7.03 & 7.23 & 7.86 \\
\hline R4 & 6.90 & 7.40 & 7.39 & 7.83 \\
\hline R5 & 7.00 & 7.16 & 7.56 & 8.00 \\
\hline Mean & 6.83 & 7.13 & 7.63 & 7.60 \\
\hline Max & 6.96 & 7.13 & 7.33 & 7.74 \\
\hline Min & 7.16 & 7.40 & 7.63 & 8.00 \\
\hline C.D. value (5\%) & 0.294 & 6.93 & 6.86 & 7.43 \\
\hline
\end{tabular}


Fig.1 Graphical representation of Sensory characteristics of mean value of goat milk whey based herbal beverage

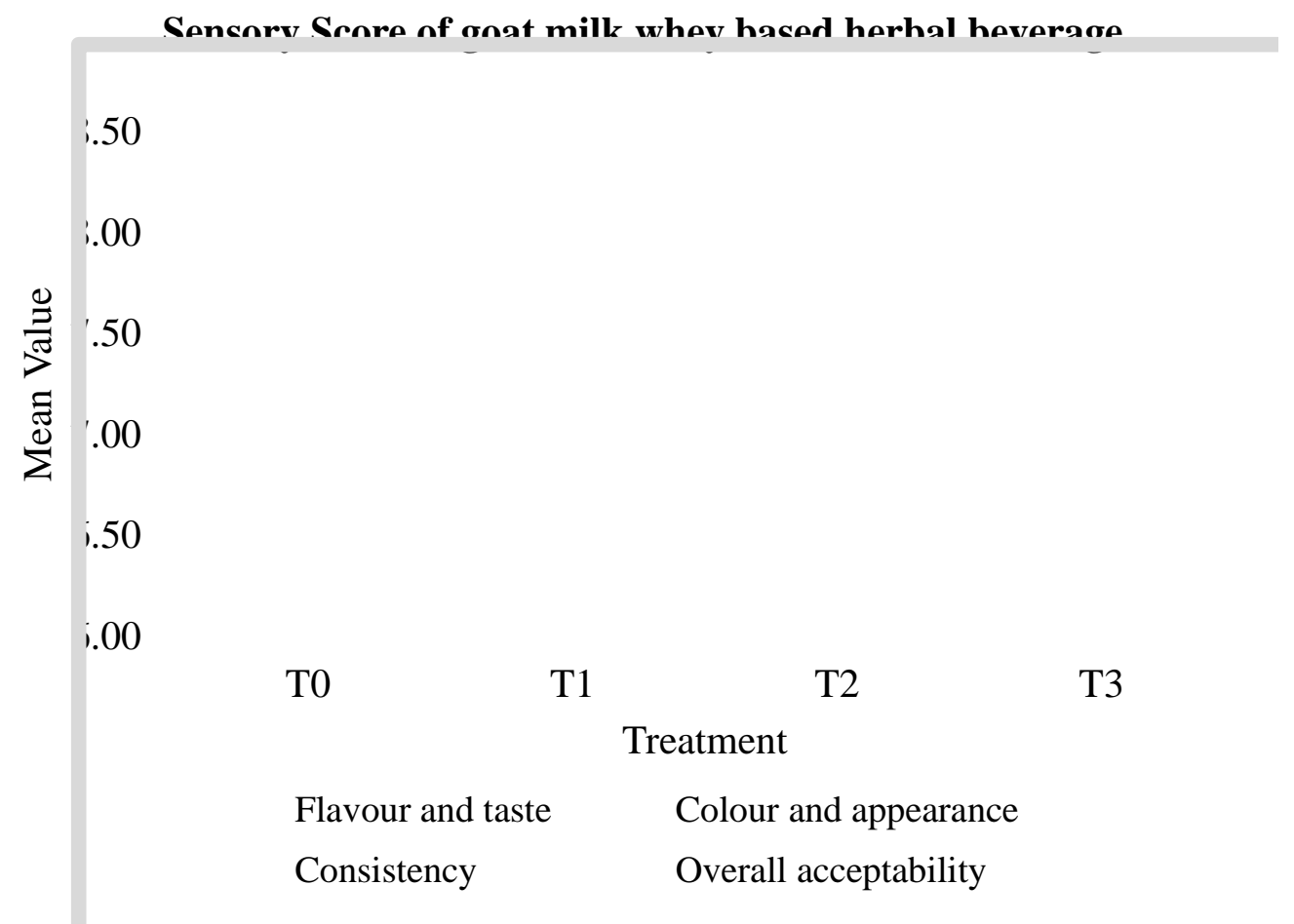

The result of ANOVA observed in the $\mathrm{F}(\mathrm{Cal})$ value (11.775) was greater than the table of $\mathrm{F}$ (3.23) at 5\% level of significance. It indicates significant effect of treatment on flavour and taste.The significant difference was further analyzed statistically to find out the C.D. between and within the different treatment combinations. The difference between the mean values of $\mathrm{T}_{0}-\mathrm{T}_{1}(0.17), \mathrm{T}_{1}-\mathrm{T}_{2}(0.20)$ less than the C.D. value, 0.314. Therefore, the difference was non significant.The difference between the mean values of $\mathrm{T}_{0}-\mathrm{T}_{2}(0.37), \mathrm{T}_{0-}$ $\mathrm{T}_{3}(0.78), \mathrm{T}_{1}-\mathrm{T}_{3}(0.61)$ and $\mathrm{T}_{2}-\mathrm{T}_{3}(0.41)$ greater than the C.D. value, 0.314. Therefore, the difference was significant.

In conclusion, the highest mean score of flavour and taste of herbal whey beverage was recorded in the sample of $\mathrm{T}_{3}(8.10)$ and lowest score was recorded $\mathrm{T}_{0}(7.12)$. Similarly, the highest mean of colour and appearance was recorded in the sample of $T_{3}(7.66)$ and lowest

mean score was recorded in $\mathrm{T}_{0}(7.00)$. This indicates that, increased in proportion of beet root in the blend increased the score for flavour and taste of herbal whey beverage. The highest mean of consistency was recorded in the sample of $T_{3}(7.36)$ and lowest was recorded in control sample $\mathrm{T}_{0}(6.78)$ and also highest mean of overall acceptability was recorded in the sample of $T_{3}(7.74)$ and lowest was recorded in sample $\mathrm{T}_{0}(6.96)$.It was concluded that highest score was observed in $\mathrm{T}_{3}$ among the all sensory characteristics of flavour and taste, colour and appearance, consistency and overall acceptability.

\section{References}

Anonymous. Goat Milk can Prevent Bacterial Diseases: case study. Science Express, New York. 1998.

Chandan RC, Attaie R, Shahani KM. Nutritional Aspects of Goat Milk and 
its Products. Proceeding of the 5th International Conference on Goats, March 2-8, New-Delhi, India, 1992; 399-420.

Dar A. Animal Husbandry Statistics, www.theopendata.com. 2012.

FAOSTAT, http://faostat.fao.org/default.aspx. 2008.

Goyal N, Gandhi DN. Comparative Analysis of Indian Paneer and Cheese Whey for Electrolyte Whey Drink, World Journal of Dairy and Food Science. 2009; 4(1): 70-72.

Kothari SK, Bhattacharya AK, Sushil Kumar and Khanuja SPS. Registration of a new chemotype Kanchan of scared basil/ holy basil Ocmium tenuiform rich in methyl eugenol. J. Medicinal and Aroma Plants. 2004; 26: 336-340.

Ohiokpehai O. Processed Food Products and Nutrient. Composition of Goat Milk. Pak. J. Nutr., 2003; 2: 68-71.

Pandya AJ and Ghodke KM. Goat and Sheep Milk Products other than Cheeses and
Yoghurt. Small Rumin. Res. 2007; 68: 193-206.

Raducuta I, Custura I, Tapaloaga D, Marmandiu A. Evolution of Goat Livestock and Goat Milk Production in the EU in the period 1999-2009. Scientific Papers Series D, vol. LIII, Animal Science, Bucharest. 2010; 229-234.

Shaikh SY, Rathi SD, Pawar VD, Agarkar BS. Studies on Development of a Process for Preparation of Fermented Carbonated Whey Beverage. J. Food Sci. Technol. 2001; 38: 519-521.

Singh B, Singh HB. Chemical composition, functional properties and processing of Beetroot a review. International J. of Scientific and Engineering Res.2014; 5 (1): 679-684.

Singh BP, Penesar, S, Nanda V. Utilization of carrot pomace for the preparation of a value added product," World Journal of Dairy and Food Sciences. 2006; 1(1): 22-27.

\section{How to cite this article:}

Nimish Kumar Lall, Sandeep G.M. Prasad, Binod Kumar Bharti, Manisha Prasad, Nikhil Sharma and Mohd Nayeem Ali. 2019. Studies on Sensory Analysis of Goat Milk Whey based Herbal Beverage. Int.J.Curr.Microbiol.App.Sci. 8(08): 1644-1651. doi: https://doi.org/10.20546/ijcmas.2019.808.194 